Do you have any notion about how that might have influenced some of these results?

Dr Weixler. What we did was we took the era effect into account, we adjusted for that in the multivariate Cox regression analysis, and there were no differences found. The surgical technique still demonstrated to be an independent risk factor for mortality. It did not change the results. We have to look into differences between previously performed Blalock-Taussig shunt versus Sano-Shunt. As for now, I can't give you an appropriate answer to this.

Dr Huddleston. The deadline for the submission of the abstracts for this meeting was sometime back in the early fall, late summer. So the surgeons at Boston Children's Hospital have had the advantage of seeing the results of this before this meeting. I presume that over the past
9 months no extracardiac conduit Fontans have been performed by the esteemed surgeons listed in this work and that only lateral tunnel Fontan procedures have been performed.

Dr Weixler. It really depends on the patient population. If you take a closer look at our results, I think that we had a slightly younger patient population compared with what is described in literature, and we still showed excellent results for young patients who needed a fenestration undergoing a lateral tunnel technique procedure. I believe I would recommend a young patient who requires a Fontan procedure with a fenestration to undergo a lateral tunnel technique and for older patients who don't necessarily need a fenestration to maybe continue using the extracardiac conduit technique.
See Article page 1480.

\section{Commentary: I don't like change}

\author{
Charles B. Huddleston, MD
}

Okay, I will admit that I do not like to change. It is difficult to see that what you have done for years may not be the right way and then head in a different direction, whether with respect to medical treatment of a particular nature, in a relationship, or in practicing surgery for congenital heart disease. I think this is particularly true for surgical techniques, where there are very few randomized studies proving that one technique is better than another (actually, that's also true for relationships). Having said that, many changes have occurred in the techniques used for congenital heart surgery-arterial switch instead of atrial switch, for example. However, perhaps no procedure has gone through as many modifications as the Fontan procedure. For the most part, these modifications seem to have improved the short- and long-term results for patients with singleventricle lesions. The early mortality for the Fontan

From the Department of Surgery, St Louis University School of Medicine, St Louis, Mo.

Disclosures: Author has nothing to disclose with regard to commercial support.

Received for publication Nov 15, 2019; accepted for publication Nov 18, 2019; available ahead of print Feb 4, 2020.

Address for reprints: Charles B. Huddleston, MD, 1465 S Grand Blvd, St. Louis, MO 63104 (E-mail: Charles.huddleston@ health.slu.edu).

J Thorac Cardiovasc Surg 2020;159:1491-2

$0022-5223 / \$ 36.00$

Copyright (C) 2019 by The American Association for Thoracic Surgery

https://doi.org/10.1016/j.jtcvs.2019.11.082

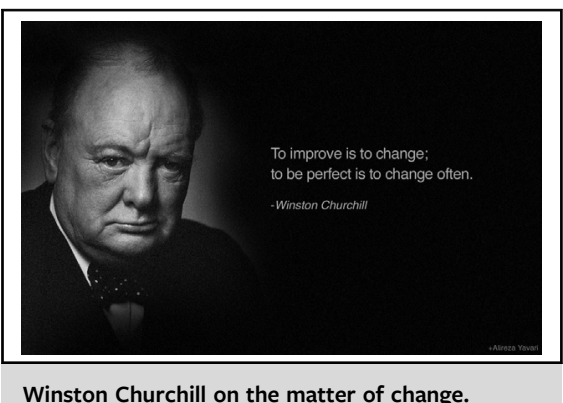

Winston Churchill on the matter of change.

CENTRAL MESSAGE

The preferred technique for the

Fontan procedure remains

controversial.

procedure in 2 early studies was very similar at $12 \% .^{1,2}$ Current results with the most recent modifications of this procedure show a mortality of $<2 \%$. ${ }^{3}$

Over the past decade, most surgeons in the United States have performed the Fontan using either the lateral tunnel intra-atrial (LT) or extracardiac (EC) technique. These 2 procedures account for $>99 \%$ of all Fontan procedures performed, with the EC technique used in $88 \%$ of cases and the LT technique used in the other $12 \%{ }^{3}$ Thus, most surgeons apparently believe that the extracardiac Fontan is better. In this issue of the Journal, Weixler and colleagues ${ }^{4}$ from Boston Children's Hospital report that the LT Fontan technique is associated with lower mortality and morbidity compared with the EC Fontan technique. Their large series spans many years. Although this is not a randomized study, the 
groups undergoing each operation appear similar in all respects, with the exception of the era in which most of the operations in each group were performed. The data certainly seem compelling. Is this one study sufficient to mandate that I (and apparently most US surgeons, including those in Boston) change from the EC to the LT Fontan technique?

This is not the first time that these 2 techniques have been compared. Previously published studies comparing the LT and EC techniques have shown no clear-cut winner but a trend toward improved results with the EC Fontan technique. These studies are listed in the references provided by the authors.

Why are the results from Boston different? One troubling point is that the early mortality for the EC Fontan group was $3.1 \%$, double the mortality reported in the most recent STS registry (and, coincidentally, the same as the last 50 patients in Fontan's originally reported series from 1983). ${ }^{1}$ The most common cause of death was related to the thromboembolic issue (baffle thrombosis and cerebral infarct) in the EC group, whereas Fontan failure was the most common cause of death in the LT group. Interestingly, none of the deaths in the EC group was attributable to Fontan failure. Certainly, baffle thrombosis is a serious complication of the Fontan procedure, but it is generally rare, and Fontan failure as a cause of death is generally common.

Why was there so much trouble with thromboembolic complications at Boston Children's Hospital? More synthetic graft material is used in the EC technique compared with the LT technique, but unless there is a fenestration, there is no connection to the left-sided circulation. However, with LT a great deal more of this foreign material is exposed to the pulmonary venous side of the circulation, where thrombotic events could be disastrous. The authors list aspirin as the sole anticoagulation strategy in the vast majority of patients. Perhaps a closer look at this is in order.

So now is decision time: change or not. We now we have this new study from a reputable center with historically excellent results. Is this single study sufficient to promote wholesale changes for the vast majority of surgeons in the United States-or even in Boston? Are the data compelling enough to abandon the extracardiac Fontan technique? For now, in deference to Churchill, I will not "improve by changing" and certainly will not approach perfection.

\section{References}

1. Fontan F, Deville C, Quaegebeur J, Ottenkamp J, Sourdille N, Choussat A, et al. Repair of tricuspid atresia in 100 patients. J Thorac Cardiovasc Surg. 1983;85:647-60.

2. Mair DD, Rice MJ, Hagler DJ, Puga FJ, McGoon DC, Danielson GK. Outcome of the Fontan procedure in patients with tricuspid atresia. Circulation. 1985;72(3 Pt 2):II88-92.

3. The Society of Thoracic Surgeons. Congenital Cardiac Database: Data Collection Sheet version 3.41. Available at: https://www.sts.org/registries-research-center/ sts-national-database/congenital-cardiac-surgery-database/data-collection. Accessed December 1, 2019.

4. Weixler V, Zurakowski D, Kheir J, Guariento A, Kaza AK, Baird CW, et al. Fontan with lateral tunnel is associated with improved survival compared with extracardiac conduit. J Thorac Cardiovasc Surg. 2020;159:1480-91.e2. 